\title{
The Changing Nature of Jobs: A Paraprofessional Time Series
}

\section{Carol P. Johnson}

This study attempts to determine if paraprofessional jobs have changed significantly as a result of automation during the period between 1975 and 1990. Three raters reviewed job descriptions dated 1975, 1981, and 1990 from the technical services department of a small academic library using the Position Analysis Questionnaire, a widely used structured job analysis tool. Analysis of the resulting data-standard z scores on thirteen overall job dimensions using ANOVA and omega-squared estimates-indicates no statistically significant differences among the jobs. Although these results show that the change in jobs over time is more idiosyncratic than expected, they may also illustrate the de-skilling effect of computers on library functions.

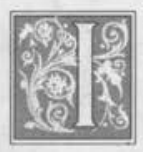

n 1984, Alan Veaner noted that "once a technology is applied to carry out very complex, routine mental work, that work is driven downward in the work hierarchy. . . . The change has provided magnificent professional enrichment opportunities for librarians and has similarly enriched the jobs of support staff." 1 This insight raises an interesting question. With the downward shift in tasks from librarians to paraprofessionals, is there evidence of a corresponding upgrade in the parapro-fessional's responsibilities? Have paraprofessional jobs changed significantly as a result of automation?

Much has been written in recent years about the working conditions and responsibilities of paraprofessionals by authors such as Charlotte Mugnier, Larry R. Oberg, and Cathleen C. Palmini. ${ }^{2-4}$ Other researchers, among them Darla Rushing and Ann Prentice, concentrated on the impact of automation on the library organization and specific departments. ${ }^{5-6}$ Scholars such as Harry Braverman and Shoshana Zuboff have written about the complicated effects of automation on the workplace from deskilling to the difficulties of managing computer-mediated work..$^{7-8}$ Specific research by Suzanne Iacono and Rob Kling indicates that technology neither automatically degrades nor improves a job. ${ }^{9}$ The differences are because of the ways in which work is organized rather than because of the technology. A search of library literature does not indicate any studies examining library paraprofessional jobs over time to determine what changes, if any, have taken place as a result of technology.

This study uses the Position Analysis Questionnaire (PAQ), a widely used structured job analysis tool, to examine, 
on a micro level, the job descriptions of three paraprofessional jobs in an academic library technical services department at a small, private liberal arts college. Dated 1975, 1981, and 1990, the job descriptions are examined to determine what, if any, changes occurred as a result of automation and to see if there are statistically significant differences among the jobs over time. To some extent, these three jobs do reflect both a job progression over time and changing responsibilities because of automation.

Structured job analysis tools differ from the job evaluation systems used to determine organizational compensation.

\section{Research into statistical methods to analyze job data for the purposes of determining job similarities and differences began in the late 1970s and 1980s for Equal Employment Opportunity Commission purposes.}

According to Roberts' Dictionary of Industrial Relations, "job analysis is the systematic investigation or study of a job or position to determine the responsibilities, duties and qualifications required to perform the job." Job evaluation is the "process of determining the classification, rating or value of an individual job in relation to the other jobs in an organization." ${ }^{10}$ Job analysis, often an informal process, provides the data for job evaluation, and typically, job evaluation systems reflect the values and politics of the local organization. This study attempts to study the jobs in question using a methodology that is not affected by local values and politics.

There are a number of more formal job analysis methods available for organizations to use. Among these are Functional Job Analysis, the Job-Element approach, the PAQ, Critical Incidents Methodology, and Task Inventories. However, this study required a job analysis tool that produces quantitative data for comparison and lim- its potential rater bias. The tool chosen was the PAQ, which rates jobs quantitatively on 187 elements of work activity and the work environment. The instrument is based on the concept that human work can be analyzed "in terms of meaningful 'units' or job elements of a workeroriented nature." 11 The designers assumed that there was a commonality across jobs resulting from the workers doing similar things and not as a result of the technology used or the product produced. ${ }^{12}$

The PAQ's present form evolved over several decades from its earliest form, The Checklist of Work Activities, developed in 1958 by Ernest J. McCormick and G. J. Palmer. In its present form, job raters respond to each of the 187 questions using Likert-format scales. These questions are organized into six divisions: (1) information input; (2) mental processes; (3) work output; (4) relationships with other persons; (5) job context; and (6) other job characteristics. Results are provided for each of these categories, plus thirteen overall dimensions. Overall dimensions include: (1) decision, communication, and general responsibilities; (2) machine/ equipment operation; (3) clerical activities; (4) technical activities; (5) service activities; (6) work schedule; (7) routine or repetitive activities; (8) work environment; (9) physical activities; (10) supervision; (11) public contacts; (12) hazardous environment; and (13) flexible schedule/optional apparel. Each division includes elements that tend to occur in combination on the job. The rater-scored sheets are analyzed by computer, and standard $\mathrm{z}$ scores are provided for each job/rater for each of the six divisions plus the overall dimensions. ${ }^{13}$

Research into statistical methods to analyze job data for the purposes of determining job similarities and differences began in the late 1970s and 1980s for Equal Employment Opportunity Commission purposes. These articles focused on the type of job analysis tool used to 
describe the job (task oriented, worker oriented, or abilities oriented) and the statistical techniques employed to analyze the data. ${ }^{14}$

In a 1977 article, Richard D. Arvey and Kevin M. Mossholder proposed the use of analysis of variance (ANOVA) combined with the omega-squared estimate to compare jobs and determine similarities for validity generalization purposes. ${ }^{15}$ In a later study, Arvey and fellow researchers found that given a reasonable sample size, the ANOVA model was an effective design in detecting true differences among jobs, but the omega-squared estimates were more useful in determining job differences even across small sample sizes. They determined that a reasonable rule of thumb would be that "values near . 30 indicate major job differences among jobs and values less than .15 indicate considerable job similarities."16

In an unpublished 1984 study, Arvey and fellow researchers hypothesized that one way to measure changes in jobs over time was to measure job description information over time using the thirteen overall dimension $\mathrm{z}$ scores generated by the PAQ. ${ }^{17}$ This article reports the findings of a statistical analysis of the PAQ results from these three positions using the ANOVA and omega-squared estimates.

\section{Methodology}

The authors derived the information for the analysis from job descriptions dated 1975,1981 , and 1990. The three jobs reflect three paraprofessional library jobs in the cataloging department of a small, academic library.

\section{Job 1}

In 1975, one position that could be described as paraprofessional existed in the cataloging department of the library. Master's-level librarians and clerks filled other positions. The position assisted the cataloging librarian in maintaining the public catalog and technical services-spe- cific files, supervising and training student employees in filing cards in the main catalog, and searching for available copy cataloging using print tools. A high school education was required, and supervisory and typing skills were useful. The training curve was estimated at six months.

\section{Job 2}

By 1981, the number of paraprofessional positions increased and two levels existed. Computerized cataloging via OCLC began in 1976. The paraprofessional in this job (level 2) located, reviewed, and modified cataloging copy in the OCLC database using the computer terminal. A second responsibility involved maintenance of the shelf list. Two years of college-level study, one year of experience as a library technician, computer training, and typing skills were necessary.

\section{Job 3}

By 1990, computers had replaced catalog cards, and database record maintenance and editing had replaced card filing. The main responsibility of the position involved database coordination, supervision of catalog entries, and media cataloging. The job now required two years of experience as a library technical assistant, level 1.

Based on the changes in selection requirements and the tasks performed, the author expected that the ANOVA model would find significant statistical differences among the jobs and reasonable omega-squared values for the job $x$ dimension effects. Three raters reviewed each job description (nine in all) to prevent biased results. They used the Job Analysis Manual for the Position Analysis Questionnaire. The raters, who were not experienced job analysts, consisted of one degreed librarian familiar with the job at the time in question; one degreed librarian who occupied a similar position in another library of the same size; and a third 


\begin{tabular}{|cccc|}
\hline \multicolumn{4}{c|}{$\begin{array}{c}\text { TABLE 1 } \\
\text { Job Evaluation Points } \\
\text { for Each Job and Rater }\end{array}$} \\
\hline \hline & Rater 1 & Rater 2 & Rater 3 \\
Job 1 (1975) & 503 & 688 & 673 \\
Job 2 (1981) & 667 & 657 & 613 \\
Job 3 (1990) & 771 & 640 & 685 \\
\hline
\end{tabular}

library staff person familiar with the job (librarian or incumbent). The results were submitted to PAQ Services, Inc., in Utah for analysis.

The PAQ results were then run on SPSS using the ANOVA model. The ANOVA model is used to detect significant differences among jobs. For the ANOVA model, the dimension scores are considered a within-job factor, the jobs, and a betweenjob factor with raters nested between jobs. A significant F-value for the between-job factor indicates that there are statistical differences between the jobs.
A significant $\mathrm{F}$-value for the job $\mathrm{x}$ dimension interaction would indicate that the profiles of the jobs are significantly different; that is, the job dimensions differ across the jobs. The omega-squared estimate is calculated when the F-values indicate significant differences among jobs to determine the proportion of variance of the job dimensions (job similarities) and the proportion of variance because of job $\mathrm{x}$ dimension (job differences).

\section{Results}

PAQ-derived job evaluation points (mean) (see table 1) for the three jobs were: job 1 (1975), 621; job 2 (1981), 645; and job 3 (1990), 698 (see the time series chart in figure 1 and table 2 for the job profiles and $\mathrm{z}$ scores on the thirteen overall dimensions). For each job and rater, the PAQ provided $z$ scores for the six divisions - information output, mental processes, work output, relationships with other persons, job context, and other job

\section{FIGURE 1}

\section{Time Series Job Comparison on PAQ Library Technician Series}

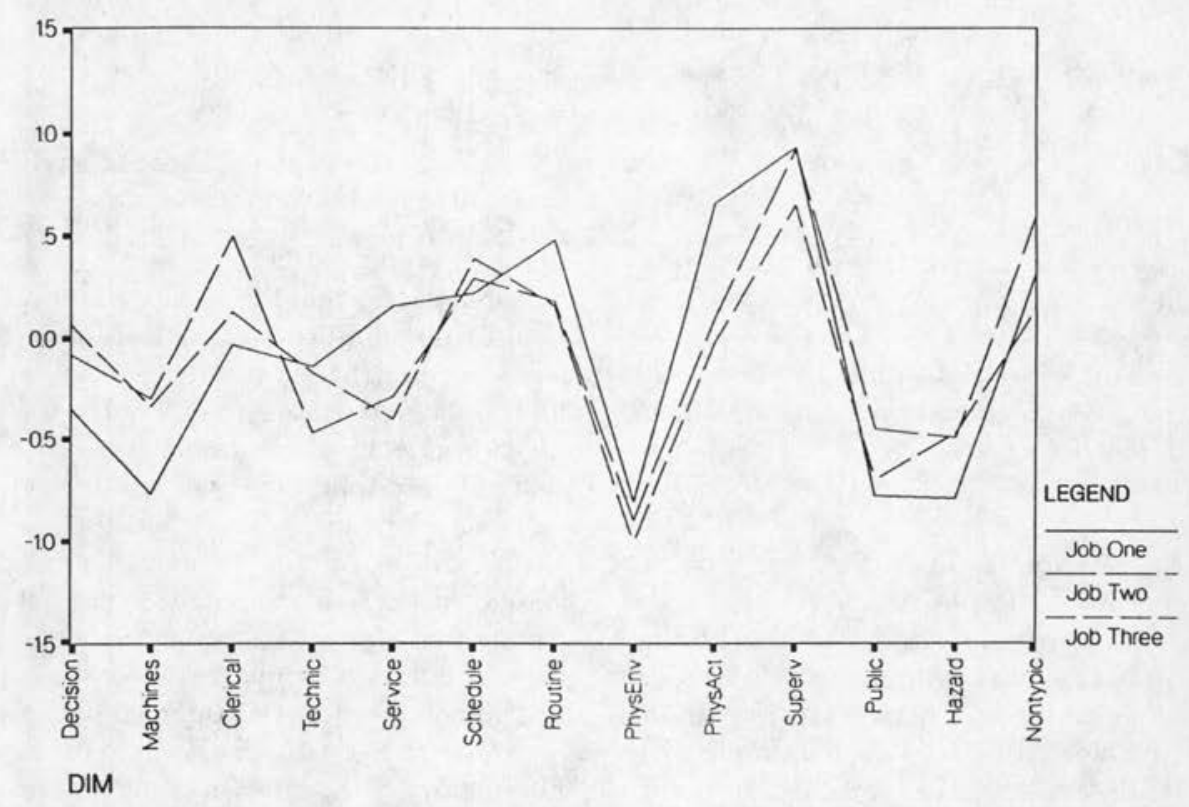




\section{TABLE 2}

\section{Z Scores on Overall Dimensions for Jobs 1-3, Mean Scores}

\section{Dimensions}

1. Having decision, communication, and general responsibilities

2. Operating machines and/or equipment

3. Performing clerical and/or related activities

4. Performing technical and/or related activities

5. Performing service and/or related activities

6. Other work schedules vs. working regular day schedules

7. Performing routing and/or repetitive activities

8. Being aware of work environment

9. Engaging in physical activities

10. Supervising/directing/estimating

11. Public and/or customer and/or related contacts

12. Working in an unpleasant/hazardous/demanding environment

13. Having a nontypical schedule/optional apparel style

$\begin{array}{cccccccccccccc}\text { Job } & \operatorname{Dim} 1 & \operatorname{Dim} 2 & \operatorname{Dim} 3 & \operatorname{Dim} 4 & \operatorname{Dim} 5 & \operatorname{Dim} 6 & \operatorname{Dim} 7 & \operatorname{Dim} 8 & \operatorname{Dim} 9 & \operatorname{Dim} 10 & \operatorname{Dim} 11 & \operatorname{Dim} 12 & \operatorname{Dim} 13 \\ 1 & -.35 & -.77 & -.03 & -.14 & .16 & .22 & .48 & -.81 & .66 & .93 & -.78 & -.79 & .32 \\ 2 & -.08 & -.30 & .50 & -.47 & -.29 & .29 & .18 & -.90 & .10 & .92 & -.45 & -.49 & .60 \\ 3 & .07 & -.34 & .13 & -.17 & -.40 & .39 & .16 & -1.01 & -.02 & .65 & -.70 & -.47 & .15\end{array}$

characteristics-as well as the thirteen overall dimensions. Researchers tested the $\mathrm{z}$ scores for the thirteen overall dimensions (see table 3 ) to determine job differences. Computed interclass correlation coefficients for each job ranged from .69 to .84 , sufficient for preceding with the ANOVA. These coefficients were minimally above the average reliability coefficient (.68) reported for a sample of over 1,000 jobs involving over 3,000 pairs of analysts in a study of the PAQ interanalyst reliability. ${ }^{18}$
The ANOVA on the thirteen overall dimension z scores (table 4) indicated no significant statistical differences among jobs, nor a significant job $\mathrm{x}$ dimension interaction. The job $x$ dimension accounted for .008 percent of the variance; the source of variance as a result of jobs accounted for .004 percent. The value resulting from the ratio of variance indicates there is almost eighteen times the variance because of job similarities than job differences. Extremely low omega-squared scores $(<.15)$ indicated very strong job similarities, not differences.

\section{TABLE 3}

\section{Z Scores on Overall Dimensions for Jobs 1-3, Raters 1-9}

$\begin{array}{rlllllllllllllll}\text { Job } & \text { Rater } & \text { Dim1 } & \text { Dim2 } & \text { Dim3 } & \text { Dim4 } & \text { Dim5 } & \text { Dim6 } & \text { Dim7 } & \text { Dim8 } & \text { Dim9 } & \text { Dim10 } & \text { Dim11 } & \text { Dim12 } & \text { Dim13 } \\ 1 & 1 & -.83 & -.84 & -.56 & . .04 & . .38 & .21 & .65 & -.60 & -.16 & 1.09 & -.58 & -.55 & .22 \\ 1 & 2 & -.08 & -.51 & .33 & .12 & -.03 & .21 & .50 & -.65 & 1.03 & .94 & -.70 & -1.35 & .59 \\ 1 & 3 & -.15 & -.95 & .16 & -.56 & .13 & .25 & .29 & -1.17 & 1.11 & .75 & -1.09 & -.49 & .16 \\ 2 & 4 & .20 & -.13 & 1.21 & -.30 & -.45 & .22 & .19 & -.90 & .46 & 1.35 & .17 & -.19 & 1.06 \\ 2 & 5 & -.14 & -.31 & .30 & -1.04 & -.12 & .25 & -.02 & -.91 & .25 & .65 & -1.02 & -.73 & .39 \\ 2 & 6 & -.28 & -.45 & .02 & -.08 & -.31 & .40 & .37 & -.88 & -.41 & .76 & -.50 & -.57 & .38 \\ 3 & 7 & .32 & -.42 & -.21 & -.18 & -.67 & .26 & -.12 & -.89 & -.17 & .72 & -.71 & -.79 & .08 \\ 3 & 8 & -.31 & -.31 & .30 & -.03 & .08 & .62 & .55 & -1.02 & -.43 & .58 & -.37 & .08 & -.12 \\ 3 & 9 & .20 & -.29 & .31 & -.31 & -.61 & .30 & .06 & -1.12 & .57 & .67 & -1.02 & -.69 & .50\end{array}$


Hypothesizing that the thirteen overall dimension scores were too abstract or general, the author ran ANOVAS on the subscores of four selected divisional sets of $\mathrm{z}$ scores:

\section{Division 1}

- Information input

- Interpreting what is sensed

- Using sources of information

- Watching devices and/or materials for information

- Being aware of environmental conditions

- Using various devices

\section{Division 2}

- Mental processes

- Making decisions

- Processing information

\section{Division 3}

- Work output

- Using machines and/or tools and/ or equipment

- Performing activities requiring general body movements

- Controlling machines or processes

- Performing skilled and/or technical activities

- Performing controlled manual and/or related activities

- Using miscellaneous equipment and/or devices

- Performing handling and/or related activities

- General physical coordination

\section{Division 4}

- Relationships with other persons Communicating judgments and/or related information

- Engaging in general personal contact

- Performing supervisory and/or coordinating and/or related activities

- Exchanging job-related information

- Public and/or related personal contacts
The ANOVA results show no significant differences for any of the four divisions.

\section{Discussion}

Test results indicate that there are no significant statistical differences among the 1975,1981 , and 1990 jobs using the ANOVA model to analyze the PAQ's thirteen overall dimensions. These results do not support a conclusion that technology has significantly upgraded the paraprofessional positions under review. Indeed, the results indicate change, but of an unexpected nature: job redesign to meet the needs of the time (old skills discarded, new ones learned), resulting in the replacement of some duties by others. Increased efficiency of work flow and operations, in this particular situation, resulted in a narrowing of functions, not an upgrading of responsibilities.

Although not statistically significant, the total mean job evaluation points have increased over time (from 621 to 698) as a result of the increased educational re-

\section{Although not statistically signifi- cant, the total mean job evaluation points have increased over time (from 621 to 698) as a result of the increased educational requirements.}

quirements. Mort McPhail of Jeanneret and Associates produced a list of twentysix PAQ elements likely to be affected by automation. He noted that technology can increase or decrease the worth of the job. Increases "in such ratings as training and experience required may be offset by decreases in items dealing with decision making, combining and analyzing information, etc., and the jobs may have become simpler and less demanding to perform."19

Also noticeable is a shift in responsibilities discernible by viewing the individual PAQ "Item With Highest Percentile Scores" sections of the PAQ reports (copies of these are available from 
the author). Supervision, which had the highest percentile score in the 1975 job and is usually valued highly in job evaluation systems, declined. The highest percentile PAQ item for the 1990 job deals with machines and equipment, not people. The next highest is inspecting, as opposed to students/trainees for the

TABLE 4

ANOVA Results on the Thirteen Overall Dimensions

\begin{tabular}{lrrrc}
\hline Source of Variation & df & MS & F & $\omega^{2}$ \\
\hline Between Jobs & & & & \\
$\quad$ Jobs (A) & 2 & .08 & & -.004 \\
$\quad$ Raters within jobs C(A) & 6 & .28 & .28 & .01 \\
Within Jobs & & & & \\
$\quad$ Dimensions (B) & 12 & 2.21 & 20.78 & .215 \\
$\quad$ Job x dimensions & 24 & .15 & 1.42 & .008 \\
Dimension x raters within & 72 & .11 & & .11 \\
jobs (B x C(A)) & & & & \\
\end{tabular}
1975 job. The 1990 job is indeed different, reflecting an apparent rearrangement of work activities brought on by automation.

The history of library automation can explain much about the changes in these three jobs. Automation for the smaller library began with cataloging functions. In the late 1970 s, the majority of libraries became members of cooperative national cataloging bibliographic utilities, such as OCLC. Shared online cataloging produced the catalog cards and machinereadable archival tapes, and changed the job structure in some cataloging departments.

The shift to online cataloging meant that more copy cataloging was done, particularly as the number of contributing libraries increased. Copy cataloging (editing a specific record to meet local library requirements) did not require the skills of a degreed librarian. Rather, it required an individual able to understand cataloging terminology, use computers, and learn the coding requirements of the bibliographic utility. Those libraries that chose to employ nondegreed library staff to perform copy cataloging incorporated these requirements by increasing the educational and training requirements for the job. All other job requirements remained the same.

This is also reflected in the duties and responsibilities of the 1981 position. "Relations with Professional Personnel" was the highest-ranking PAQ item for this job.
Paraprofessionals performed the same duties as some librarians: copy cataloging and supervision. Automation at this time contributed to the confusion of roles between professional and paraprofessional.

A review of division 4 (relationships with other persons) z scores supports the above contention that job responsibilities have changed. It is evident that the 1990 position requires more judgment communication, less general personal contact, less supervisory responsibility, and less public contact than the two previous jobs. The 1976 automation of cataloging functions increased the job level (1981) by including copy cataloging; but by 1990, a narrowing of job function had occurred as librarians learned to adapt office automation strategies of work flow and efficiency to cataloging functions. The 1990 job provides more responsibility for database management but decreased supervisory responsibility.

\section{Conclusion}

This study began as an effort to understand the impact of computers on the paraprofessional jobs in the technical service department of one library, anticipating a statistically significant difference. The author believed that the addition of OCLC copy cataloging to the 1981 position, and definitely the addition of database record maintenance and media cataloging to the 1990 position, would make 
a statistically significant difference. This did not occur. Perhaps this is the result of the unique job history or pattern for this particular library, or it may result from the PAQ's worker orientation (as opposed to task orientation), which may not discriminate sufficiently to measure the "real" job difference. Duplication of the study in other libraries should be undertaken to see if similar results are found.

In this particular case, technology, often viewed as a way to upgrade the status of library positions, does not seem to have raised the job level. One reviewer of this article noted that it seems "counter intuitive" that increasing levels of required education do not make a differ-

\section{Technology, a better educated work force, fewer accredited library schools, and the continuing democ- ratization of the information process will all continue to exacerbate the problem in the future.}

ence. Although qualifications (KSAs) are used as data in the PAQ, in this case the unique blend of responsibilities in each job resulted in some dimensions, highly valued in job evaluation systems, decreasing. Others, also highly valued, stayed the same or increased. The combination of increases, balanced against decreases was not enough to produce a statistically significant difference.

All libraries attempt to recruit staff with high qualifications; however, this is a subjective judgment area. With the changing work environment, the question of what qualifications are necessary to perform the work at each level of the library organization is a legitimate subject for research. This study attempted to find a tool that would examine jobs over time with as little bias as possible, but further studies are needed to answer that question. The paraprofessional jobs under review have not been significantly upgraded because the responsibilities that upgrade positions and typically lead to better pay (typically, autonomy; authority, including supervisory responsibility; and decision-making) are not reflected in the jobs under review.

The national adoption of MARC as the preferred way for most libraries to catalog library materials has resulted in the standardization of cataloging rules and practices. MARC copy cataloging computerizes and standardizes the level of decision making. This permits non-MLS staff to take over the bulk of copy cataloging. As Shoshana Zuboff noted, "the purpose of the intelligent technology at the core of a computer system is to substitute algorithms or decision rules for individual judgments. This substitution makes it possible to formalize the skills and know-how intrinsic to a job and integrate them into a computer program." 20

This study indicates that automation has not upgraded technical services library paraprofessional positions as much as the author had thought. The functions remain the same, but the tools change (and the level of the person doing the work). However, this study did not investigate the intrinsic rewards that technology may add to jobs by including responsibilities that are more interesting and central to the operation of libraries. There are new jobs in libraries that did not exist prior to the introduction of computers; it would be interesting to identify these and compare them with the more traditional jobs of libraries. The future library will have both. Real improvement in the status of paraprofessionals is dependent upon the level of authority, autonomy, and skill assigned to the jobs they fill. This will not occur without further study of the necessary qualifications for all levels of library work and the appropriate ways to obtain those qualifications.

Technology is a means, not an end; and it is not the answer to the increasing uncertainty that besets the profession. The deskilling effects of computers certainly 
complicate an already complex situation. Technology, a better educated work force, fewer accredited library schools, and the continuing democratization of the information process will all continue to exacerbate the problem in the future. Re- searchers need more data to clarify both paraprofessional and professional positions and their respective roles in libraries. Job analysis using tools such as the PAQ may provide useful data to aid in the discussion.

\section{Notes} 25.

1. Alan B. Veaner, "Librarians: The Next Generation," Library Journal 109 (Apr. 1, 1984): 623-

2. Charlotte Mugnier, The Paraprofessional and the Professional Job Structure (Chicago: ALA, 1980).

3. Larry R. Oberg, Mark E. Mentges, P.N. McDermott, and Vitoon Harusadangkul, "The Role, Status, and Working Conditions of Paraprofessionals: A National Survey of Academic Libraries," College \& Research Libraries 53 (May 1992): 215-38.

4. Cathleen C. Palmini, "The Impact of Computerization on Library Support Staff: A Study of Support Staff in Academic Libraries in Wisconsin," College \& Research Libraries 55 (Mar. 1994): 119-27.

5. Darla H. Rushing, "Caught in the Middle: Systems, Staff and Maintenance in the MediumSized Academic Library," Journal of Library Administration 13 (1990): 157-73.

6. Ann E. Prentice, "Jobs and Changes in the Technological Age," Journal of Library Administration 13 (1990): 47-57.

7. Harry Braverman, Labor and Monopoly Capital; The Degradation of Work in the Twentieth Century (New York: Monthly Review Pr., 1974).

8. Shoshana Zuboff, In the Age of the Smart Machine: The Future of Work and Power (New York: Basic Bks., 1988).

9. Suzanne Iacono and Rob Kling, "Changing Office Technologies and Transformations of Clerical Jobs," in Technology and the Transformation of White-collar Work, ed. Robert E. Kraut (Hillsdale, N.J.: L. Erlbaum Associates, 1987).

10. Roberts' Dictionary of Industrial Relations, 4th ed. (Washington, D.C.: Bureau of National Affairs, 1994).

11. Ernest J. McCormick, Paul R. Jeanneret, and Robert C. Mecham, "A Study of Job Characteristics and Job Dimensions as Based on the Position Analysis Questionnaire (PAQ)," Journal of Applied Psychology Monograph 56 (Aug. 1972): 247-368.

12. Benjamin Schneider and Neal Schmitt, Staffing Organizations, 2nd ed. (Glenview, Ill.: Scott, Foresman and Co., 1986).

13. Ernest J. McCormick, Robert C. Mecham, and Paul R. Jeanneret, Technical Manual for the Position Analysis Questionnaire, 2nd ed. (PAQ Services Inc., 1989).

14. Edwin T. Cornelius III, Theodore J. Carron, and Marianne N. Collins, "Job Analysis Models and Job Classification," Personnel Psychology 32 (1979): 693-708.

15. Richard D. Arvey and Kevin M. Mossholder, "A Proposed Methodology for Determining Similarities and Differences among Jobs," Personnel Psychology 30 (1977): 363-74.

16. Richard D. Arvey and others, "Detecting Job Differences: A Monte Carlo Study," Personnel Psychology 34 (1981): 709-30.

17. Richard D. Arvey and others, Skills Obsolescence: Psychological and Economic Perspectives (unpublished paper, 1984).

18. McCormick, Mecham, and Jeanneret, Technical Manual for the Position Analysis Questionnaire.

19. Mort McPhail, PAQ Items Likely to Be Impacted by Office Automation (Logan, Utah: Jeanneret Associates, 1990).

20. Shoshana Zuboff, "New Worlds of Computer-Mediated Work," Harvard Business Review 60 (Sept./Oct. 1982): 142-52. 